\title{
Absence of skin sensitivity to oxides of aluminium, silicon, titanium or zirconium in patients with Crohn's disease
}

\author{
J C W Lee, S Halpern, D G Lowe, A Forbes, J E Lennard-Jones
}

\begin{abstract}
Background-Some metallic compounds, especially of zirconium, can cause cell mediated granulomatous inflammation of the skin. Pigment granules containing compounds of aluminium, silicon, and titanium have been observed within macrophages in the wall of the small intestine in health and in Crohn's disease. Zirconium compounds can be ingested in toothpaste.
\end{abstract}

Aim-To determine in a pilot study if granulomatous sensitivity can be detected to compounds of these metals or silicon after injection into the skin of patients with Crohn's disease.

Subjects-Eight patients with Crohn's disease known to have had granulomata in the intestine and not currently treated with corticosteroids, and two healthy controls.

Method-Two intradermal injections each of $0.1 \mathrm{ml}$ of a $0.02 \%$ suspension of one of the compounds made in the abdominal wall of each subject. The site was marked and full thickness skin biopsy performed six weeks later.

Result-A foreign body granuloma was observed on histological examination of two biopsy specimens but no evidence of a cell mediated response in any subject.

Conclusion-No support was found for the hypothesis that Crohn's disease is due to a specific sensitivity to ingested metallic or silicon compounds.

(Gut 1996; 39: 231-233)

Keywords: Crohn's disease, skin sensitivity, aluminium, silicon, titanium, zirconium.

St Mark's Hospital, London

J C W Lee

A Forbes

J E Lennard-Jones

Departments of

Dermatology

$S$ Halpern

and Histopathology

D G Lowe

St Bartholomew's Hospital, London

Correspondence to: Professor J E Lennard-Jones, St Mark's Hospital, Northwick Park, Watford Road, Harrow, Middlesex HA1 3UJ.

Accepted for publication 19 January 1996 been implicated as the cause of some human diseases. Zirconium lactate, when applied to the matous reaction in a few subjects. ${ }^{12}$ Pulmonary granulomatous lesions are associated with occupational exposure to compounds of titanium, beryllium, and aluminium. ${ }^{3-5}$

In podoconiosis, an endemic but non-filarial form of elephantiasis, there is severe oedema of the lower limbs as a consequence of obstructive lymphadenopathy. It has been proposed that this is caused by fibrosis of the afferent lymphatics as a result of absorption of microparticles of silica and alumino-silicates through the skin where people walk barefoot on certain types of soil. Particles containing silica, titanium, and aluminium are present in microgranulomata within inguinal lymph nodes of sufferers. ${ }^{6}$ Granulomata also develop in response to intradermal injection of colloidal silica in healthy subjects but these are foreign body granulomata and are clearly distinguishable from the cell mediated response to small quantities of zirconium lactate. ${ }^{7}$

As metals and minerals are ubiquitous in the community, a hypersensitivity to these substances in some people rather than a direct toxic effect is the most probable pathogenetic mechanism by which they may contribute to disease. Experiments with metal compounds by skin testing provide a useful model for the study of the evolution of granulomatous lesions in hypersensitive people. After intradermal injection of small quantities of zirconium lactate or beryllium oxide, a distinct epithelioid cell granulomatous reaction can be found in sensitive subjects compared with a foreign body reaction to larger amounts in non-susceptible subjects. ${ }^{2} 8$

The gastrointestinal tract is exposed daily to metallic compounds from diverse dietary sources, either intentionally as with food additives, or unintentionally via cooking utensils. Small amounts of toothpaste, containing zirconium compounds, may be swallowed. Interestingly, toothpaste has been postulated as a possible cause of $\mathrm{CD} .{ }^{9}$

A black granular pigment containing aluminium, silica, and titanium has been described within the intestinal wall of adults, including those affected by CD. The pigment is found in macrophages concentrated in the lymphoid aggregates of the small bowel, and in some cases also in the mesenteric lymph nodes. ${ }^{1011}$

We have tested the hypothesis that patients with CD are sensitive to certain metal compounds or to the mineral silica by conducting intradermal skin testing on patients in a pilot study. skin can cause a specific cell mediated granulo-

\section{Methods}

Subjects studied

Eight patients (seven men and one woman) with $\mathrm{CD}$ and two healthy male subjects volunteered for the study. The duration in time since 
$\mathrm{CD}$ had been diagnosed ranged from four to 27 years, with a median of 13.5 years. Terminal ileum involvement by $C D$ had been reported in all of the patients. In seven patients, surgical resection of diseased bowel had been required in the past, including six with two or more resections. The median time interval between surgical removal of bowel, in which histological evidence of granulomata within diseased intestine was found, and skin testing was five years and ranged from one to 10 years. For the remaining patient who had not required operative treatment, granulomata had been found in colonic biopsy specimens obtained during endoscopy 12 years previously. Six patients were receiving maintenance treatment with mesalazine or sulphasalazine and one also with azathioprine. Two patients were not receiving any specific treatment for $C D$. None of the patients studied required treatment with corticosteroids for at least two months prior to and during the study. The study was approved by the district research ethics committee.

\section{Choice of substances used and their physical characteristics}

Four inorganic substances were selected for testing - zirconium oxide $\left(\mathrm{ZrO}_{2}\right)$, titanium oxide $\left(\mathrm{TiO}_{2}\right)$, aluminium oxide $\left(\mathrm{Al}_{2} \mathrm{O}_{3}\right)$, and silica $\left(\mathrm{SiO}_{2}\right)$, obtained from Degussa (Cheshire, UK). The first three were chosen because of the known association of compounds of these metals with diseases characterised by granulomatous hypersensitivity reactions and the presence of two of them in pigment within intestinal wall. Silica was used as a non-specific substance, which can cause a granulomatous skin response.

The compounds had a purity greater than $96 \%$ and the average sizes of the primary particles were $12\left(\mathrm{SiO}_{2}\right), 13\left(\mathrm{Al}_{2} \mathrm{O}_{3}\right), 21\left(\mathrm{TiO}_{2}\right)$, and $30 \mathrm{~nm}\left(\mathrm{ZrO}_{2}\right)$. Although their crystal structures vary, they never exist as isolated primary particles, tending to form aggregates and agglomerates (technical information supplied by Degussa).

\section{Preparation and intradermal injection of inorganic substances}

A $0.02 \%(w / v)$ suspension (1 in 5000) of each substance (4 mg of compound diluted in $20 \mathrm{ml}$ sterile water) was autoclaved for 20 minutes at $121^{\circ} \mathrm{C}$ before use. Each subject was tested with two substances. A volume of $0.1 \mathrm{ml}$ of each suspension was injected intradermally at separate sites on the anterior abdominal wall, which were tattooed with India ink for future identification of the area. After six weeks the skin test sites were biopsied under local anaesthesia with a standard disposable punch biopsy instrument of $4 \mathrm{~mm}$ diameter, and examined for histological evidence of a granulomatous reaction. In two patients biopsies were done after seven and nine weeks respectively.

\section{Results}

\section{Patients with $C D$}

Except for a short period of localised pain at the time of injection, no patient reported any other side effect. There were no visible nor palpable papules at the injection sites for the duration of the study prior to skin biopsy. Serial sections from each biopsy specimen were examined under light microscopy. Histological evidence of a loose granuloma around foreign material (silica) was observed as the only significant abnormality in one of 16 sites tested. There was no evidence of an inflammatory response or other reaction to the injected metals in the other biopsy sites tested. Inorganic material was not identified in any of the histological sections in the remaining biopsy sites under light microscopy.

\section{Controls}

Of the two control subjects studied, a foreign body type granuloma (to zirconium oxide) was present in one of four skin sites tested. As with CD patients, there were no side effects except for minor localised discomfort at the time the compounds were injected intradermally.

\section{Discussion}

The aim of the study was to identify whether specific granulomatous sensitivity to inorganic substances exists in patients with $C D$. The results have not provided evidence that patients with $\mathrm{CD}$ are prone to develop skin granulomata after intradermal exposure to inorganic substances. Compounds of the three metals used are known to be associated with a granulomatous reaction in human tissue, ${ }^{1-6}$ and appropriately we have used elements that are found in the granular pigment identified within diseased bowel wall. ${ }^{1011}$ Furthermore compounds of these elements are likely to be ingested in small quantities: aluminium (from cooking utensils, anti-caking agent), titanium (artificial colouring), silica (thickening and anti-caking agent), and zirconium (toothpaste). ${ }^{12}$

Elias and Epstein demonstrated, by intradermal skin testing of minute quantities of zirconium lactate and beryllium oxide, that only people known to be sensitive to these metals developed a distinct epithelioid granulomatous reaction, whereas a nonspecific foreign body inflammatory response was seen in non-sensitive subjects when injected with larger doses. ${ }^{8} \mathrm{~A}$ granulomatous skin reaction has also been described in certain subjects after injections of vaccine that contain an aluminium compound. ${ }^{13}$ It may be that if inorganic substances have a part to play in the pathogenesis of $C D$, only a few members of the general population are sensitive. In this study, we were careful in our selection of patients, ensuring all had histological evidence of granulomata within their diseased intestine. Furthermore, as corticosteroids may influence the immune response, no patient had required treatment with systemic corticosteroids for at 
least two months, and in most instances longer, before the test injection.

As the alimentary tract is exposed continually to ingested substances, the possibility that one or more of these is responsible for CD is plausible. Dark pigment containing metal particles in the bowel wall are found in macrophages within Peyer's patches, which mediate sampling and processing of inert particles from the lumen of the bowel. Experiments in animals have shown that insoluble polystyrene particles of $50 \mathrm{~nm}$ to $3 \mu \mathrm{m}$ are taken up mainly by Peyer's patches, transported to the serosa, and thence by mesenteric lymphatic vessels to lymph nodes ${ }^{14}$; particles of titanium $500 \mathrm{~nm}$ in diameter are handled similarly. There is some evidence to suggest that intestinal permeability is increased among CD patients and their healthy relatives, suggesting this could be an important initiating factor in the pathogenesis of CD. ${ }^{15}$

Skin testing may not be the most appropriate method to test for suspected sensitivity as the immunological and inflammatory response to foreign substances by the skin is probably different from that in the gastrointestinal tract. However, it would be difficult and perhaps potentially harmful, to test human subjects by requesting them to ingest metallic compounds for a period before intestinal biopsies.

The concentration of the suspensions we tested and the duration of time they were left in situ before the skin sites were biopsied may be important determinants of the response. A $0.02 \%$ suspension ( 1 in 5000 ) of the compounds was used and this is comparable to published concentration of 1 in 10000 and 1 in 1000 , which have evoked a specific granulomatous response in zirconium lactate sensitive subjects, within six weeks of intradermal testing. ${ }^{18}$ More concentrated preparations of $1 \%$ to $4 \%$ produce a foreign body type of response. We are not aware of any guidelines recommended for intradermal testing with compounds of aluminium, titanium or silicon.

In animal experiments, dogs fed on a daily ration of finely divided sand or talcum powder developed intestinal inflammation with pronounced lymphoedema and pathological features similar to regional ileitis. ${ }^{16}$ However, it should be noted these foreign particles were fed to the animals daily, in comparatively large quantities, and all animals developed macroscopic and histological lesions. Thus this is probably not a hypersensitive reaction, but a non-specific toxic response.

The results of our study do not suggest that specific skin sensitivity to the three metals compounds tested or to silica is present in $\mathrm{CD}$ patients. As skin biopsy is invasive we did not test further patients in this pilot study. The presence of metallic particles within diseased bowel wall most probably results from intestinal absorption, but without pathological consequence, as it also occurs in health.

We are grateful to Degussa, Cheshire, UK, for supplying the inorganic metal compounds used in the study.

1 Shelley WB, Hurley HJ. The allergic origin of zirconium deodorant granulomas. $\mathrm{Br} \mathcal{f}$ Dermatol 1958; 70: deodoran

2 Epstein WL, Skahen JR, Krasnobrod H. Granulomatous hypersensitivity to zirconium: localisation of allergen in tissue and its role in formation of epithelioid cells. F Invest Dermatol 1963; 38: 223-32.

3 Kriebel D, Brain JD, Prince NL, Kazemi H. The pulmonary toxicity of beryllium. Am Rev Respir Dis 1988; 137: 464-73.

4 Chen W, Monnat RJ, Chen M, Mollet NK. Aluminium induced pulmonary granulomatosis. Hum Pathol 1978; 9: 705-11.

5 Shigemtsu N, Matsuba K, Watanabe K, et al. A granulomatous lung disease produced by titanium. In: JonesWilliams W, Davies BH, eds. Sarcoidosis and other granulomatosis diseases. Cardiff: Alpha Omega, 1980 728-33.

6 Price EW. Podoconiosis: non-filarial elephantiasis. Oxford: Oxford University Press, 1990.

7 Shelley WB, Hurley HJ. The pathogenesis of silica granulomas in man: a non-allergic colloidal phenomena. F Invest Dermatol 1960; 34: 107-22.

8 Elias PM, Epstein WL. Ultra-structural observations on experimentally induced foreign-body and organised epithelioid cell granulomas in man. Am F Pathol 1968; 52: epithelioid $1207-16$.

9 Sullivan SN. Hypothesis revisited: Toothpaste and the cause of Crohn's disease. Lancet 1990; 336: 1096-7.
cante

10 Shepherd NA, Crocker PR, Smith AP, Levison DA Exogenous pigment in Peyer's patches. Hum Pathol 1987; 18: $50-4$.

11 Powell J, Ainley CC, Kendall MD, Dhillon AP, Sankey EA, Thompson RPH. Specific inorganic microparticles in gut tissue may initiate Crohn's disease. Gut 1991; 32: A572.

12 Hanssen M. E for additives. London: Thorsons, 1987.

13 Fawcett HA, Smith NP. Injection-site granuloma due to aluminium. Arch Dermatol 1984; 120: 1318-22.

14 Jani P, Halbert GW, Langridge J, Florence AT Nanoparticulate uptake by the rat gastro-intestinal mucosa: quantitation and particle size dependency. mucosa: quantitation and particle

15 May GR, Sutherland LR, Medding JB. Is small intestinal permeability really increased in relatives of patients with Crohn's disease? Gastroenterology 1993; 104: 1627-32.

16 Chess S, Chess D, Olander G, Benner W, Cole WH. Production of chronic enteritis and other systemic lesions by ingestion of finely divided foreign material. Surgery $1950 ; 27: 221-34$ 